\title{
CONTRIBUIÇÃO DA TOMOGRAFIA DE FEIXE CÔNICO CONE BEAM PARA DIAGNÓSTICO DE DENTE SUPRANUMERÁRIO: RELATO DE CASO
}

Camila Pinheiro FURQUIM, Ilana Sanamaika Queiroga BEZERRA, Fernando Henrique WESTPHALEN, Ângela FERNANDES, Antonio Adilson Soares De LIMA

O aparecimento de um ou mais dentes que excedam a quantidade normal esperada para cada dentição é denominado de supranumerário. É um tipo de anomalia cuja etiologia ainda é desconhecida, pode ocorrer de várias formas, tamanhos e em diferentes locais do arco dentário. Dentes supranumerários que irrompem entre os incisivos são chamados de mesiodente, após $\circ 3^{\circ}$ molar são os distomolares e entre molares e prémolares são os paramolares ou pré-paramolares. Ocorre com maior prevalência na maxila e o mais comum é o mesiodente. $O$ objetivo desse trabalho é relatar um caso de supranumerário mandibular em localização atípica. Paciente do sexo feminino, 22 anos queixa-se da presença de uma estrutura pequena e endurecida entre os dentes inferiores. O exame clínico e os recursos de imagens revelaram a presença de um dente supranumerário localizado entre os dentes 46 e 47 cujo diagnóstico foi de um paramolar. A literatura revela que esta anomalia dentária é rara, principalmente entre $01^{\circ} \mathrm{e}$ $2^{\circ}$ molar mandibular. Atualmente, os recursos imaginológicos são imprescindíveis para o correto diagnóstico, pois em alguns casos os dentes estão fusionados o que dificulta a sua remoção; e se a imagem não for bem detalhada pode induzir o profissional ao erro.

Palavras-chave: Dente supranumerário; Dente Molar; Tomografia; Diagnóstico. 